\title{
SOLUTE TRANSPORT MODELING IN OVERLAND FLOW \\ APPLIED TO FERTIGATION
}

\author{
by \\ P. García-Navarro, ${ }^{1}$ Assoc. Member ASCE, \\ E. Playán, ${ }^{2}$ Assoc. Member ASCE \\ and N. Zapata ${ }^{3}$
}

\section{SUMMARY}

A numerical model for overland water and solute flow is presented. The proposed model is applied to the simulation and management of surface fertigation systems. The model successfully simulates the results of field experiments and proves its advantage over previous surface fertigation models based exclusively on solute advection.

\section{KEYWORDS}

Overland Flow, Solute Transport, Advection-Diffusion, Fertigation, Border, Basin

\footnotetext{
${ }^{1}$ CPS, Universidad de Zaragoza. ACTUR. 50015 Zaragoza, Spain. pigar@posta.unizar.es

2 Dept. Genética y Producción Vegetal, Laboratorio de Agronomía y Medio Ambiente CSIC-DGA, EEAD-CSIC. Apdo. 202, 50080 Zaragoza, Spain. playan@eead.csic.es ${ }^{3}$ Dept. Soils and Irrigation. Laboratorio de Agronomía y Medio Ambiente CSIC-DGA, SIA-DGA. Apdo. 727, 50080 Zaragoza, Spain.nery@eead.csic.es
} 


\section{ABSTRACT}

A model of solute transport in overland flow is developed and applied to the simulation of surface fertigation. Water flow is simulated using the depth-averaged, one-dimensional shallow water equations. Solute flow is represented by an advectiondiffusion model. The resulting set of three partial differential equations is sequentially solved at each time step. First, water flow is computed using the explicit two-step McCormack method. Based on the obtained velocity field, solute transport is explicitly determined from the advection-diffusion equation using the operator split technique. Four field experiments involving fertigation events on an impervious free-draining border were performed to validate the proposed model and to obtain estimates of $K x$, the longitudinal dispersion coefficient. A value of $K x=0.075 \mathrm{~m}^{2} \mathrm{~s}^{-1}$ satisfactorily reproduces the field experiments. The model is also applied to the simulation of a fertigation event on a pervious border. A sensitivity analysis is performed to assess the dependence of fertilizer distribution uniformity on the value of $K x$. Finally, the proposed model is compared to a previous model based on pure advection.

\section{INTRODUCTION}

Fertigation is an interesting alternative for the fertilization of surface irrigated crops. The limitations to the use of surface fertigation stem from the alleged low uniformity and efficiency of surface irrigation systems. Hanson et al. (1995) reported that the performance of typical surface irrigation systems in California cannot be statistically distinguished from that of pressurized irrigation systems. Clemmens and Dedrick (1994) arrived at a similar conclusion when discussing the potential application efficiency of different irrigation systems. Recent developments in the design and 
management of surface irrigation have led to new perspectives of an ancient irrigation system that has reached the $21^{\text {st }}$ century with a dominant position over the new pressurized systems.

The simulation of surface fertigation has been attempted as a means to evaluate its potential and to substitute intense, resource-consuming field experimentation. Boldt et al. (1994) presented a simulation model for surged furrow irrigation based on pure advection. Playán and Faci (1997) presented an advection model for border irrigation. In this case, the model was applied to the simulation of border strips, including level basins as a particular case. In the reference, ten field experiments were reported, involving analyses of water and soil samples. The model was first used to reproduce the experimental results. The performance index used for fertilizer application was the distribution uniformity as presented by Merriam and Keller (1978). The model was able to explain $44 \%$ of the experimental variability in distribution uniformity. Finally, the model was applied to the simulation of different fertigation cases differing in field slope, infiltration and downstream boundary condition. In each case, fertigation strategies were assessed by simulating all possibilities of starting and ending times of fertilizer application. A contour line map was used to represent distribution uniformity for all possible combinations of the starting and ending times.

The physical process of solute transport in overland flow is referred to as hydrodynamic dispersion (Cunge et al. 1980). It represents the interaction between advection and turbulent diffusion, both depending on the flow velocity field. Therefore, advective transport is a strong simplification of the actual phenomenon. Some of the 
limitations of fertigation models based on advection were pointed out by Playán and Faci (1997) when comparing experimental data with model predictions.

Taylor (1921) established the basis of diffusion modeling in turbulent flows. Holly (1975) presented the basic Fickian equations for mass transport in two dimensional overland flows. In the last decades, applications of this theory to several disciplines related to water quality in coastal and inland waters have been presented (Falconer 1992). Recent works in advection-diffusion simulation in free-surface water bodies (Karpik and Crockett 1997; Komatsu et al. 1997) have been based on the separate numerical treatment of the two distinct transport processes: advection by the mean flow and diffusion by turbulent eddies. In order to obtain an accurate simulation of the advective part of the dispersion process, a non-diffusive numerical scheme is required. To satisfy this requirement, other authors have used semi-Lagrangian schemes (Cheng et al. 1984; Islam and Chaudhry 1997). An alternative to the semi-Lagrangian approach would be to use an Eulerian upwind scheme of the appropriate order.

In the present work, a hydrodynamic model of overland flow including solute transport is formulated and applied to surface fertigation. The resulting model is validated using four ad-hoc field experiments and one of the experiments reported by Playán and Faci (1997). Simulation of the experimental results is used to issue recommendations about the model parameters related to solute transport. Model validation is completed with a sensitivity analysis to the dispersion coefficient, and finally a comparison of the proposed model with an advection model is presented. 


\section{MATHEMATICAL MODEL}

The dynamics of the flow system have been described with the help of a system of three partial differential equations that, essentially, express mass and momentum balance for the liquid and mass balance for the solute. The liquid is actually a two-phase mixture but the concentrations are low enough to justify a model similar to those customarily used for pure water. The low solute concentration implies that water flow determines the solute fate. The contrary is not true.

The mathematical model presented is depth-averaged so that all properties are assumed uniform in the vertical and the pressure is considered to follow a hydrostatic distribution at each section. Hence, the water flow description follows a shallow water model with extra infiltration terms. The mass balance for the solute is a depth-averaged advection-diffusion equation.

The nature of the system of equations is such that a sequential resolution is possible. Therefore, the procedure applied to each time step has been to solve first for the water flow equations and then, given the flow depth and velocity, to integrate the solute concentration evolution.

\section{Water Flow}

The one-dimensional shallow water flow equations are a simplified model that can be written in cartesian coordinates and vectorial form for a unit width rectangular channel as:

$$
\frac{\partial \mathbf{U}}{\partial t}+\frac{\partial \mathbf{F}}{\partial x}=\mathbf{G}
$$


For a descriptive deduction see Cunge et al. (1980). In that system, $\mathbf{U}=(h, u h)^{T}$ represents the vector of conserved variables (wetted cross section and discharge per unit width), where $h$ and $u$ are the depth and the velocities in the $x$ direction respectively. The flux in the second term of the equations is,

$$
\mathbf{F}=\left(u h, u^{2} h+\frac{g h^{2}}{2}\right)^{T}
$$

The right hand side of the system contains the sources and sinks of momentum arising from the bed slopes, the friction losses along the flow direction and the effects due to the loss of water through infiltration to the soil.

$$
\mathbf{G}=\left(-i, g h\left(S_{0}-S_{f}\right)+D_{i}\right)^{T}
$$

The bed and friction slopes are,

$$
S_{0}=-\frac{\partial z}{\partial x} ; S_{f}=\frac{n^{2} u|u|}{h^{4 / 3}}
$$

where $z$ is the bottom elevation and $n$ is the Manning roughness coefficient. The infiltration rate, i, can be computed using the empirical Kostiakov-Lewis equation, $i=k a \tau^{a-1}+f_{0}$ where $\tau$ is the opportunity time measured in minutes and $k, a$ and $f_{0}$ are empirical parameters. The momentum transfer is estimated as: 


$$
D_{i}=\frac{u i}{2}
$$

\section{Solute Flow}

The amount of substance in the fluid is specified by the concentration, $C$, that is the mass of substance per unit volume of fluid. The transport of this substance is assumed to take place by means of two mechanisms, advection and diffusion. Advection-diffusion equations are very common in fluid dynamic problems in general and in hydraulic engineering in particular. Advection represents the pure transport of the unchanged concentration along the pathlines of the fluid particles. Diffusion, according to Fick's law, states that the transport of concentration in a motionless fluid is proportional to the negative of the concentration gradient. Fick's law is based on molecular transport in which the constant of proportionality, the diffusion coefficient, depends on both the fluid and the solute properties. Actual processes are mostly governed by the influence of turbulence in the flow. Usually, this effect is included in the equations as an extra diffusion term that, in practical situations, is the most relevant and is formulated as Fick's law with a turbulent diffusion coefficient. This is in general a three dimensional phenomenon that can be described by

$$
\frac{\partial C}{\partial t}+\frac{u_{i} \frac{\partial C}{\partial x_{i}}}{\text { advection }}=\frac{\frac{\partial}{\partial x_{i}}\left(\varepsilon_{x i} \frac{\partial C}{\partial x_{i}}\right)}{\text { diffusion }}
$$

In (6), Einstein's summation rule has been applied, $u_{i}$ corresponds to the $i$-component of a three-dimensional velocity vector and $\varepsilon_{x i}$ represents the turbulent diffusion coefficient in direction $x_{i}$. 
Equation (6) is too general for the interest of our work. In the context of a depth averaged model, the depth averaged concentration is of primary interest and it has been shown that, under special conditions, eq. (6) leads to a much simpler advectiondiffusion model (Holly 1975):

$$
\frac{\partial(h C)}{\partial t}+\frac{\partial(h u C)}{\partial x}=\frac{\partial}{\partial x}\left(h K_{x} \frac{\partial C}{\partial x}\right)
$$

In (7), $u$ and $C$ are the depth-averaged velocity and concentration, and $K_{x}$ is an empirical longitudinal dispersion coefficient that should not be confused with the turbulent diffusivity. In general, $K_{x}$ incorporates dispersion due to differential advection as well as turbulent diffusion (Cunge et al. 1980).

\section{NUMERICAL MODEL}

\section{Water Flow}

In recent years there has been a significant amount of work published in reference to numerical techniques applied to the shallow water equations. Some of this work has been developed in the specific application of overland flow for irrigation purposes. The numerical scheme used in the present paper for discretizing system (1) is the explicit McCormack in two steps predictor-corrector (McCormack 1971). It is a shock-capturing extended technique of proved efficiency for unsteady free surface flow modeling. It allows the simulation of hydraulic flows involving shocks traveling along a fixed grid (no shock tracking is necessary). For details about this method see Fennema and Chaudhry (1986) and García-Navarro and Savirón (1992). Being second order accurate in space and time, it offers good resolution and has great conceptual simplicity. 
The simulation requires initial conditions. In the present application these were the values representing a dry border, that is, $\mathrm{h}(\mathrm{x}, 0)=10^{-5} \mathrm{~m} ; \mathrm{u}(\mathrm{x}, 0)=0 \mathrm{~m} \mathrm{~s}^{-1}$. As any other linear second order method, it may suffer from oscillatory behavior near discontinuities (the advancing front, in this case) and may render anomalous results near critical points (Froude $=1$ ).

Subcritical wave propagation over a dry bed did not involve shock fronts. Instead, numerical instabilities arose from the presence of important source terms at the advancing front. A pointwise semi-implicit discretization proved efficient in reducing this kind of instabilities (Playán and García-Navarro 1997).

\section{Boundary Conditions}

Having used an explicit scheme for the interior points, the theory of characteristics has to be applied to specify conditions at the border boundaries. A detailed description of the principles of this method may be found in several references (Cunge et al. 1980). The flow regime at the upstream and downstream ends determines the number of required boundary conditions. The application to a prismatic onedimensional channel is well described in García-Navarro and Savirón (1992). The application to border irrigation was presented in Playán and García-Navarro (1997).

\section{Solute Flow}

For the numerical solution of eq. (7), a splitting technique was adopted. It is based on two steps as suggested by Karpik and Crockett (1997). First, the advectiondiffusion equation is written as: 


$$
\frac{\partial C}{\partial t}+L(C)=0 \quad L=L_{1}+L_{2} \begin{cases}L_{1} \rightarrow & \text { advection } \\ L_{2} \rightarrow & \text { diffusion }\end{cases}
$$

Then, for every time step $\Delta t=t^{n+1}-t^{n}$, the equation is solved in a sequence

1. $\frac{\partial C}{\partial t}+L_{1}(C)=0 \quad C=C^{n} \quad t \in\left(t^{n}, t^{n+1}\right) \quad \Rightarrow \quad C^{*}$

2. $\frac{\partial C}{\partial t}+L_{2}(C)=0 \quad C=C^{*} \quad t \in\left(t^{n}, t^{n+1}\right) \quad \Rightarrow \quad C^{n+1}$

that provides the value of the concentration at the new time. The procedure followed is outlined next.

\section{Step1: Advection}

The advective part of equation (7) can be algebraically manipulated so that

$$
\frac{\partial(h C)}{\partial t}+\frac{\partial(h u C)}{\partial x}=0 \quad \rightarrow \quad \frac{\partial C}{\partial t}+u \frac{\partial C}{\partial x}=0
$$

This form represents clearly the invariance of a scalar $C$ along a trajectory

$$
\frac{D C}{D t}=0 \quad \text { along } \quad \frac{d x}{d t}=u
$$

In order to obtain a good approximation of the function $C(x, t)$ at all the points $x_{i}$ of a fixed discrete grid, assuming that $C$ and $u$ are known everywhere in the grid at an earlier 
time, the departure point $x_{0}$ of the trajectory arriving in $x_{i}$ must be determined first. This position will not coincide in general with a grid point. Then, a way of calculating $C\left(x_{0}\right)$ must be established, that is, an adequate interpolation technique is necessary. And finally

$$
C\left(x_{i}, t^{n+1}\right)=C\left(x_{0}, t^{n}\right)
$$

The above summarizes the semi-Lagrangian method for the solution of a scalar problem. The actual implementation for the present problem is based on a cubic interpolation since it is more accurate than a linear interpolation and less oscillatory than a quadratic interpolation. Hermite cubic polynomials have been chosen for their simplicity, accuracy and the important advantage of allowing the calculation of the derivatives from the solution itself. To provide the interpolated value of a function $f(x)$ defined in a discrete mesh at a point $x_{p}, x_{i} \leq x_{p} \leq x_{i+1}$ :

$$
f\left(x_{p}\right)=c_{1}\left(x_{p}-x_{i}\right)^{3}+c_{2}\left(x_{p}-x_{i}\right)^{2}+c_{3}\left(x_{p}-x_{i}\right)+c_{4}
$$

where the coefficients are

$$
c_{1}=\frac{d_{i+1}+d_{i}-2 \Delta_{i}}{\Delta x_{i}^{2}}, \quad c_{2}=\frac{-d_{i+1}-2 d_{i}+3 \Delta_{i}}{\Delta x_{i}}, \quad c_{3}=d_{i}, \quad c_{4}=f\left(x_{i}\right)
$$

the discrete slopes are defined as 


$$
\Delta_{i}=\frac{f_{i+1}-f_{i}}{x_{i+1}-x_{i}}
$$

and the space derivatives at the nodes are estimated in the case of an interior point by

$$
d_{i}=\frac{-\Delta_{i-2}+7 \Delta_{i-1}+7 \Delta_{i}-\Delta_{i+1}}{12}
$$

Slightly different formulae are used for the points that do not have two neighbors on both sides. The monotonicity of this cubic interpolant is enforced by first imposing some conditions and limits on the values of the derivatives. For more details see Williamson and Rasch (1989), for other applications see García-Navarro and Priestley (1994) and for another Hermite cubic based method see Holly and Preissmann (1977).

\section{Step2: Diffusion}

For the numerical solution of the parabolic equation representing the diffusion process

$$
\frac{\partial(h C)}{\partial t}=\frac{\partial}{\partial x}\left(h K_{x} \frac{\partial C}{\partial x}\right)
$$

A standard central difference scheme has been applied

$$
(h C)_{i}^{n+1}-(h C)_{i}^{*}=\frac{\Delta t}{\Delta x}\left[\left(h K_{x}\right)_{i-1} \frac{(h C)_{i-1}^{*}-(h C)_{i}^{*}}{x_{i}-x_{i-1}}-\left(h K_{x}\right)_{i+1} \frac{(h C)_{i}^{*}-(h C)_{i+1}^{*}}{x_{i+1}-x_{i}}\right]
$$

where the values $C^{*}$ represent those calculated from the advection step. 
Boundary conditions for this part are applied at both ends of the domain, fixing the value of the concentration upstream and that of its spatial derivative downstream. During fertilizer application the value of concentration was set to the normalized value of one. A value of zero was used otherwise. The spatial derivative of fertilizer concentration at the downstream end of the border was set to zero.

The amount of fertilizer infiltrated at node $i$ during a time step $\Delta t$ can be computed as:

$$
\text { Fert }_{i}=\Delta t i_{i} \frac{C_{i}^{n}+C_{i}^{n+1}}{2}
$$

As time progresses, this quantity is accumulated. The uniformity of the infiltrated fertilizer is used as an index of the quality of the fertigation event. For this matter, the fertilizer distribution uniformity of the low quarter $D U L Q_{F}$ (Merriam and Keller 1978) has been used:

$$
D U L Q_{F}=\frac{\text { Average low quarter fertilizer application }}{\text { Average fertilizer application }} 100
$$

\section{MODEL VALIDATION AND TESTING}

Validation of the model was accomplished using five field experiments. Four of them were performed during the course of this research, and the fifth one was reproduced from the literature. When planning the field experiments, attention was paid to the fact that the solute transport module introduces a new parameter in the model: the longitudinal dispersion coefficient $K x$. Under these conditions, there are four parameters in the model that can not be readily measured: $n, k, a$ and $K x$. The roughness parameter 
is often estimated from a visual appreciation of the state of the soil surface. Infiltration can be measured in borders and basins using a variety of field techniques (Merriam and Keller 1978). These techniques are based on measurements on a small portion of soil, and the resulting estimates of the infiltration parameters are often not representative of the average field conditions. Numerical techniques have been developed in the last decades to estimate infiltration and/or roughness from the advance and recession curves of an irrigation event (Katopodes et al. 1990). The usefulness of these algorithms is inversely related to the number of unknown parameters. When consideration was given to the problems related to parameter estimation, we decided to run the field experiments on an impervious border. In this way, only two parameters would be left in the model: $n$ and $K x$. The experimental procedure would involve estimation of $n$ from the hydraulics of the experiment, and estimation of $K x$ from the movement of the solute in the irrigation water. The practical implementation of the no-infiltration experiments required covering the experimental field with a PVC film. To increase the hydraulic roughness of PVC and make it similar to that of a commercial border, a fine layer of subcentimetric gravel was evenly spread over the film. The impervious border represents an approximation to the soil surface conditions commonly found in border irrigation.

The experiments on the impervious borders were used for model validation and for the estimation of an appropriate value for $K x$. Such experiments are not subjected to the spatial variability of infiltration (due to the impervious bed) and roughness (due to the manufactured nature of the bed). An additional experiment involving standard irrigation conditions was obtained form the literature. The bromide experiment described by Playán and Faci (1997) was used for the purpose of assessing the validity 
of the estimated value of $K x$ in real irrigation conditions (with infiltration and with a natural soil surface).

The proposed model was used to reproduce the experimental results. Linear and cubic interpolations were used in the model runs. A zero value of $K x$ was used in both cases for testing purposes. In the case of cubic interpolation, a value was determined based on best fit to the experimental results on part of the data set. The proposed value of $K x\left(0.075 \mathrm{~m}^{2} \mathrm{~s}^{-1}\right)$ was verified on the rest of the experiments.

\section{Experiments on an Impervious Border}

A free-draining border was constructed at the research facilities of the SIA in Zaragoza, Spain with the following characteristics: the border was $200 \mathrm{~m}$ long and 2.00 $\mathrm{m}$ wide, with a slope of $0.000671 \mathrm{~m} \mathrm{~m}^{-1}$. The area where the border was constructed had just been laser leveled, as indicated by the fact that the standard deviation of the elevation residuals with respect to the elevation regression line was $14 \mathrm{~mm}$. The water was supplied from a low pressure pipe. A volumetric water meter was installed at the supply pipe upstream from a sliding gate used for flow regulation to predetermined values. Two types of experiments were run on the impervious border. In the steady cases a fixed inflow was applied to the border until uniform flow conditions were reached. At this time, a fertilizer application was made. In the unsteady cases, the discharge was applied over the dry border bed and the fertilizer was applied when the advancing front had covered approximately $25 \%$ of the border area. The steady state experiments were used to estimate a value for $K x$ that was validated using the unsteady experiments. 
The fertilizer used in this experiment was granulated ammonium nitrate. The total mass of fertilizer was divided in weighed containers that were applied at the upstream end of the border every $5 \mathrm{~s}$. To accelerate the solution process, the irrigation stream was mechanically stirred at the fertigation point. Three stations were marked on the border at distances 50, 100 and 150 m from the inlet. At each station water samples were collected at 30 to $60 \mathrm{~s}$ intervals during the passage of the fertilizer plume. The correlation between fertilizer concentration and electrical conductivity (EC), described by Playán and Faci (1997), was used to characterize the solute concentration. A field EC-meter was used to determine at each station the start and end of the sampling operation. A laboratory test was performed to determine the regression line of fertilizer concentration corresponding to the fertilizer and irrigation water used in the experiments. The resulting equation was:

$$
C=0.790 \text { EC }-1.527 \quad R^{2}=0.996
$$

where $\mathrm{C}$ is expressed in $\mathrm{g} \mathrm{L}^{-1}$ and EC is expressed in $\mathrm{dS} \mathrm{m}^{-1}$. The electrical conductivity of the irrigation water was $1.69 \mathrm{dS} \mathrm{m}^{-1}$. In each experiment, the initial fertilizer concentration was determined as the ratio of total fertilizer mass to the volume of fertilized water, computed as the irrigation discharge times the fertilizer application time. The relative fertilizer concentration was computed as the ratio of actual fertilizer concentration to initial fertilizer concentration. Sample processing at each station provided a history of relative concentration. 


\section{Steady Cases}

Two experiments were performed on a steady flow $(Q)$ of $5.0 \mathrm{~L} \mathrm{~s}^{-1} \mathrm{~m}^{-1}$. Both experiments were based on an initial fertilizer concentration of $7.78 \mathrm{~g} \mathrm{~L}^{-1}$. The experiments differed in the fertilizer application time ( $\mathrm{Ta}$ ), with values of 180 and 360 s. One way to estimate Manning $n$ is to measure uniform flow depth and use Manning equation. We found two practical problems of measuring flow depth: First, the use of gravel over the PVC film made it difficult to measure flow depth, since the channel bed could be considered to be at the PVC film level or at the top of the gravel layer. Second, field surface undulations led to visually appreciable differences in flow depth. Therefore, a large number of field elevation observations would have been required to obtain an adequate estimate of $n$. Therefore, we decided to estimate Manning $\mathrm{n}$ from the solute concentration history at the stations. The hypothesis is that the peak value of relative concentration at each station corresponds to the same fluid particle.

Velocity estimates were obtained for each experiment between stations 50 and $100 \mathrm{~m}$ and between 100 and $150 \mathrm{~m}$, respectively. The average velocity was $0.101 \mathrm{~m} \mathrm{~s}^{-1}$, and the coefficient of variation was 9.5\%. A value of $n=0.04$ was obtained from Manning equation and used to simulate both experiments. Holly (1986) used Elder’s theory of turbulent flow (based on Taylor's analysis) to present equations that lead to the computation of $K x$ based on hydraulic parameters. The theoretical value of $K x$ for this experiment was $0.006 \mathrm{~m}^{2} \mathrm{~s}^{-1}$.

The experimental data (Fig.1) shows concentration histories for both experiments and for the three stations. The curves show some skew to the right, 
indicating that the fertilizer recession front was not as abrupt as the advancing front. For $T a=180 \mathrm{~s}$, the peak values of relative concentration at the three stations show a continuous decay in time. In the case of $T a=360 \mathrm{~s}$, the peak values are similar at stations 50 and $100 \mathrm{~m}$, and some decay is observed at $150 \mathrm{~m}$. These differences between experiments are attributed to the longer application time in the second experiment. Simulation results reproduce the experimental results with variable accuracy. In the three simulated cases it can be observed some anticipation of the simulation results with respect to the observed data. This time lag, evaluated in $100 \mathrm{~s}$, is attributed to the time required for the dissolution of the fertilizer. Linear interpolation with $K x=0 \mathrm{~m}^{2} \mathrm{~s}^{-1}$ results in strong numerical dispersion. The results are always similar to those obtained with cubic interpolation and $K x=0.075 \mathrm{~m}^{2} \mathrm{~s}^{-1}$. When cubic interpolation was used with $K x=0 \mathrm{~m}^{2} \mathrm{~s}^{-1}$, the results were similar to the expected rectangular wave with unit relative concentration. This is particularly true for the long application time. Cubic interpolation with a $K x$ value of $0.075 \mathrm{~m}^{2} \mathrm{~s}^{-1}$ showed satisfactory agreement with most of the six concentration histories. The simulated results reproduce the observed skew of the relative concentration. The theoretical value of $K x$ resulted too small and did not produce satisfactory agreement with the experimental values.

\section{Unsteady Cases}

The unsteady cases consisted of complete free-draining border irrigation events. Two experiments were performed differing on the inflow discharge and the application time. The first experiment was characterized by $Q=2.4 \mathrm{~L} \mathrm{~s}^{-1} \mathrm{~m}^{-1}$ and $T a=180 \mathrm{~s}$. The initial fertilizer concentration was $8.22 \mathrm{~g} \mathrm{~L}^{-1}$. The irrigation time was 2,698 s, with fertilizer application starting at 1,033 s. The observed time of advance was 4,476 s. In the second experiment the inflow was set to $5.9 \mathrm{~L} \mathrm{~s}^{-1} \mathrm{~m}^{-1}$ and $T a=360 \mathrm{~s}$. The initial 
fertilizer concentration was $6.64 \mathrm{~g} \mathrm{~L}^{-1}$. The irrigation time was 2,265 s, with fertilizer application starting at $500 \mathrm{~s}$. The observed time of advance was 2,760 s.

The estimation of Manning $n$ was based on reproducing the advance curve using simulation. The overland flow routines described in this work were applied to the simulation of advance in both experiments using different tentative values of $n$. In both cases, a value of 0.09 provided the best fit to the experimental data. It has to be noted that steady state experiments on the same border using similar inflows resulted in a much smaller estimate of Manning $n$. Nevertheless, agreement was found between the two steady experiments and between the two unsteady experiments. At the same time, simulations with the respective values of Manning $n$ satisfactorily reproduced the experimental data in each case. The Manning equation was originally formulated for steady flows, although it is often extrapolated to estimate friction head losses in unsteady flows. Chow (1959) identified a series of factors affecting the numerical value of the friction parameter, stressing the fact that surface roughness should not be considered to be the only one. The theoretical values of $K x$ for the first and second experiments were 0.007 and $0.015 \mathrm{~m}^{2} \mathrm{~s}^{-1}$, respectively.

The experimental results show lower peak values than in the steady cases, although the initial concentrations are similar (Fig. 2). In coincidence with the steady experiments, there is a time lag between simulations and observations. In this case, the lag is inversely proportional to the inflow and initial fertilizer concentration. This trend is to be expected if the dissolution of the fertilizer granules is considered as the cause of the lag. 
Cubic interpolation with $K x=0 \mathrm{~m}^{2} \mathrm{~s}^{-1}$ resulted in the highest peak values of relative concentration, although in this experiment, dispersion was strong even in this case. The results of the cubic interpolation with $K x=0.075 \mathrm{~m}^{2} \mathrm{~s}^{-1}$ are often confounded with those for the linear interpolation with $K x=0 \mathrm{~m}^{2} \mathrm{~s}^{-1}$, particularly in the case with $Q=5.9 \mathrm{~L} \mathrm{~s}^{-1} \mathrm{~m}^{-1}$. The simulation results for $K x=0.075 \mathrm{~m}^{2} \mathrm{~s}^{-1}$ show a satisfactory agreement with the experimental observations, indicating that this value of the dispersion coefficient can be used to simulate surface fertigation for a range of inflows. In coincidence with the steady cases, the experimental value of the dispersion coefficient is higher than the theoretical values.

\section{Experiment on a Pervious Border}

The bromide experiment presented by Playán and Faci (1997) was characterized by the application of pulverized potassium bromide to the irrigation stream of a blocked-end border. The border length was $255 \mathrm{~m}$, and $Q=4.53 \mathrm{~L} \mathrm{~s}^{-1} \mathrm{~m}^{-1}$. The field was laser leveled to a slope of $0.0010 \mathrm{~m} \mathrm{~m}^{-1}$. The infiltration coefficients were: $k=0.00656$ $\mathrm{m} \min ^{-\mathrm{a}}, a=0.4347$ and $f_{0}=0.00000$. Manning $n$ was estimated as 0.03 . The irrigation time was 2,640 s, with fertilizer application starting at $1080 \mathrm{~s}$, with $T a=420 \mathrm{~s}$. The time of advance was 3,720 s. The initial concentration of $\mathrm{Br}^{-}$was $1.535 \mathrm{~g} \mathrm{~L}^{-1}$.

\section{Simulation of Relative Concentration}

Figure 3 presents the experimental data, together with the simulation results. In this case, the differences between the three simulations are small in comparison with the previous experiments. The agreement between the experimental data and the cubic interpolation with $K x=0.075 \mathrm{~m}^{2} \mathrm{~s}^{-1}$ is satisfactory, and adds to the representativity of the proposed value for the dispersion coefficient in surface irrigation. It is worth noting 
that the time lag observed in the previous experiments between experimental and computational data is not apparent in this case. In our opinion, the difference is due to the physical presentation of the fertilizer: pulverized instead of granulated. In the last two stations model simulations seem to be delayed from the experimental data. This circumstance can be attributed to the spatial variability of infiltration or soil surface elevation. Flow in this area of the border should be very sensible to these effects, since by the time of fertilizer advance to both stations the inflow had already been cut off.

\section{Sensitivity Analysis to $\mathrm{Kx}$}

One of the objectives of this research is to recommend a value for the dispersion coefficient in border fertigation. Up to this point, the use of $K x=0.075 \mathrm{~m}^{2} \mathrm{~s}^{-1}$ has resulted in satisfactory simulation of five field experiments. This value is higher than the theoretical values corresponding to each experiment by a factor of between 5 and 12. This discrepancy should be addressed by future research works based on the comparison of field experiments and computer simulations.

The purpose of this section is to assess the effect on irrigation uniformity of an error in the estimation of $K x$. The sensitivity analysis was based on four fertigation strategies applied to the bromide experiment. The cases were named S1 to S4. In all cases fertilizer application started at 377 s. The application ended at times 754, 1,131, 1,250 and 1,886 s for cases S1, S2, S3 and S4, respectively. In each case, simulation was performed with cubic interpolation and eleven values of $K x$ ranging from 0.000 to $0.125 \mathrm{~m}^{2} \mathrm{~s}^{-1}$. 
Simulation results (Fig. 4) indicate that when the $D U L Q_{F}$ is extremely low (as in S1) $K x$ has little effect on $D U L Q_{F}$, with a trend to increase with it. When the values of $D U L Q_{F}$ are intermediate (as in S2 and S3), the $D U L Q_{F}$ can increase 15 points in the considered range of $K x$. Finally, for high values of $D U L Q_{F}$ the effect can be the contrary, resulting on a moderate decrease in the fertigation uniformity as $K x$ increases.

The relevance of $K x$ on $D U L Q_{F}$ indicates that further research should be devoted to establish the validity of the proposed value for the dispersion parameter. Cases exploring a wide variety of hydraulic conditions should be experimentally analyzed to obtain better sustained estimates of the dispersion coefficient. The different experiments reported in this work were compatible with values of $K x$ in the range of 0.05 to 0.10 $\mathrm{m}^{2} \mathrm{~s}^{-1}$. In this range, the variation of $D U L Q_{F}$ is restricted to \pm 3 points, a value that can be considered moderate.

\section{Comparison with an Advection Model}

The proposed model has proven its capability to reproduce the solute concentration histories at different points down a fertigated border. This represents a significant improvement over advection models, and can lead to better estimates of fertigation uniformity. In order to establish the validity of the advection model presented by Playán and Faci (1997), a comparison between both models was prepared based on the simulation of the bromide experiment. The methodology consisted of the elaboration of contour line maps of $D U L Q_{F}$ using as variables the starting and ending times for fertilizer application. The irrigation time was divided into intervals of $377 \mathrm{~s}$. The choice of this interval was dictated by its similarity to the experimental application time (the shortest simulated application time will be similar to that used in the field 
experiment) and the evenness of the division. To cover all possible application strategies, 28 simulations were required.

The results of both models (Fig. 5) show some similarity, particularly with respect to the poor performance of short applications starting too early or too late. The area of high performance is not particularly coincident, with the proposed model locating good prospects for short applications applied between one-third and one-half of the irrigation time, a rule commonly applied by farmers using surface fertigation. Both models coincide in that the best practice is to apply the fertilizer uniformly with irrigation water during the whole event, a common practice when liquid fertilizers are used and relevant runoff or percolation losses are not expected.

In Fig. 6 model estimations of $D U L Q_{F}$ are compared using a scatter plot. The differences between both models can be analyzed referring to the sensitivity analysis for $K x$. In fact, $\mathrm{Kx}=0 \mathrm{~m}^{2} \mathrm{~s}^{-1}$ implies advective transport, although in this case numerical diffusion has a clear effect on the simulation results. In coincidence with Fig. 4, when the uniformity is moderate, the advective model severely underestimates $D U L Q_{F}$. On the other hand, when uniformity is high, a moderate overestimation of $D U L Q_{F}$ results. In this particular case, the average uniformities (for the 28 simulations) for both models are practically identical.

\section{SUMMARY AND CONCLUSIONS}

The solute transport routine of the proposed model has proved to be an adequate tool to reproduce the evolution of solute concentration with time at different points of an irrigated border following a pulsed fertigation event. The experiments on an 
impervious border led to the selection of adequate simulation parameters, since preventing infiltration reduced the number of parameters to two. The hydraulics of the irrigation event was used to estimate Manning $n$. The value of this parameter for the steady state experiments resulted less than half of the corresponding value for the unsteady experiments. Similarly, a value of the longitudinal dispersion coefficient $(K x)$ was selected seeking agreement between the observed and model simulated relative concentration histories. The steady state experiments were used for the estimation of $K x$, and the unsteady experiments served the purpose of model validation.

In all simulations, linear interpolation resulted in high numerical diffusion. As expected, cubic interpolation proved effective in reducing numerical diffusion, and the choice $K x=0 \mathrm{~m}^{2} \mathrm{~s}^{-1}$ resulted in peak values of fertilizer relative concentration close to 1 in the steady state experiments. In the unsteady experiments, use of cubic interpolation without longitudinal dispersion did not prove so effective: the peak values of relative concentration fell well below 1 in most cases. The recommended value for the longitudinal dispersion coefficient, $K x=0.075 \mathrm{~m}^{2} \mathrm{~s}^{-1}$, satisfactorily reproduced the observed time evolution of relative fertilizer concentration in both the steady and unsteady experiments. The simulation of an experiment on a pervious border taken from the literature confirmed the applicability of the model to the simulation of border fertigation and added to the validity of the estimate of $K x$.

The fact that a unique value of $K x$ has resulted in satisfactory simulation of the different experiments (differing in flow conditions, infiltration and discharge values) does not imply endorsement of this value for all surface fertigation applications. If no additional information is available, the proposed value could be tentatively used. The 
sensitivity analysis showed that only moderate changes in fertilizer distribution uniformity ( \pm 3 points) should be expected if $K x$ ranges between 0.05 and $0.10 \mathrm{~m}^{2} \mathrm{~s}^{-1}$.

The comparison between the proposed model and a previous model based on pure advection revealed significant differences in the estimated fertilizer distribution uniformity. Both models were coincident in that short fertilizer applications towards the beginning or the end of the irrigation event should be avoided. The proposed model identified an area of high uniformity located at the center of Figure 5. This area did not show in the contour line map when the advective model was used. A scatter plot of the DULQF $_{F}$ estimated by both models revealed that the advection model strongly underestimated uniformity when uniformity was low (below $40 \%$ as estimated with the proposed model), and overestimated uniformity in the rest of the cases. To avoid these errors in the estimation of fertilizer uniformity, the use of a model based on the advection-diffusion equation is strongly recommended. Further research should be devoted to compare both types of models with field experiments under a wide range of experimental conditions.

We believe that the proposed model can be used as a tool to optimize fertilizer management in surface irrigated areas. Application of a fertigation model can result in lower deep percolation and runoff losses of fertilizers. Optimizing the use of agricultural inputs and adopting environment-friendly farming practices are the key to the sustainability of irrigated agriculture. 


\section{ACKNOWLEDGEMENTS}

The authors would like to express their gratitude to the CONSI+D of the Government of Aragón, Spain. Their grant PCA1094 made this research possible. Thanks are also due to the INIA of the Government of Spain for granting a scholarship to N. Zapata. 


\section{APPENDIX I. REFERENCES}

Boldt, A. L., Watts, D. G., Eisenhauer, D. E. and Schepers, J. S. (1994). "Simulation of water applied nitrogen distribution under surge irrigation." Trans. ASAE, 37(4), 1157-1165.

Cheng, R. T., Casulli, V. and Milford, S. N. (1984). "Eulerian-Lagrangian solution of the convection-dispersion equation in natural coordinates" Water Resour. Res., 20, 944-952

Chow, V. T. (1959) Open-channel hydraulics. McGraw-Hill, Tokio.

Clemmens, A. J. and Dedrick, A. R. (1994) "Irrigation techniques and evaluations." Adv. series in agricultural sciences. K. K. Tanji and Yaron, B., Eds. SpringerVerlag, Berlin, 64-103.

Cunge, J. A., Holly, F. M. and Verwey, A. (1980) Practical aspects of computational river hydraulics. Pitman Publishing Limited, London.

Falconer, R. A. (1992). “Flow and water quality modeling in coastal and inland water”. Journal of Hydraulic Research 30(4), 437-452.

Fennema, R. J. and Chaudhry, M. H. (1986). "Explicit numerical schemes for unsteady free-surface flows with shocks”. Water Resour. Res., 22(13), 1923-1930. 
García-Navarro, P., and Savirón, J.M. (1992). "McCormack's method for the numerical simulation of one-dimensional discontinuous unsteady open channel flow." J. of Hydraulic Research, 308(1), 95-105.

García-Navarro, P. and Priestley, A. (1994) “A conservative and shape-preserving Semi-Lagrangian method for the solution of the shallow water equations”, Int. J. for Num. Methods in Fluids, 18, 273-294.

Hanson, B., Bowers, W., Davidoff, B., Kasapligil, D., Carvajal, A. and Bendixen, W. (1995) "Field performance of microirrigation systems," In: Microirrigation for a changing world: Conserving resources/Preserving the environment. Proc., Fifth Int'l. Microirrigation Congress., Orlando, Florida.

Holly, F. M. (1975). “Two-dimensional mass dispersion in rivers”. Hydrology paper no. 78, Colorado State University. Fort Collins, Colorado.

Holly, F.M. and Preissmann, A. (1977) “Accurate calculation of transport in two dimensions”, ASCE J. of Hydraulic Engineering, 103, 1259-1277.

Holly, F. M. (1986) "Dispersion in rivers and coastal waters - 1. Physical principles and dispersion equations." Developments in hydraulic engineering. P. Novak, Ed. Elsevier, London, 1-37. 
Islam, M. R. and Chaudhry, M. H. (1997). "Numerical solution of transport equation for applications in environmental hydraulics and hydrology”. Journal of Hydrology, 191:106-121.

Karpik, S.R. and Crockett, S.R. (1997). "Semi-Lagrangian algorithm for twodimensional advection-diffusion equations on curvilinear coordinate meshes”. ASCE J. of Hydraulic Engineering, 123(5), 389-400.

Katopodes, N. D., Tang, J. and Clemmens, A. J. (1990). "Estimation of surface irrigation parameters." ASCE J. Irrig. Drain. Div., 116(5), 676-696.

Komatsu, T., Ohgushi, K. and Asai, K. (1997). "Refined numerical scheme for advective transport in diffusion simulation”. ASCE J. of Hydraulic Engineering, 123(1):41-50.

McCormack, R. W. (1971). "Numerical solution of the interaction of a shock wave with a laminar boundary layer." Lecture Notes in Physics. Springer-Verlag, Berlin, Germany. 8, 151-163.

Merriam, J. L. and Keller, J. (1978) Farm irrigation system evaluation: a guide for management. Utah State University, Logan, Utah. 271 pp.

Playán, E. and Faci, J. M. (1997). "Border fertigation: field experiments and a simple model." Irrig. Sci., 17, 163-171. 
Playán, E. and García-Navarro, P. (1997). "Radial flow modeling for estimating levelbasin irrigation parameters." J. Irrig. Drain. Div., ASCE, 123(4), 229-237.

Taylor, G. I. (1921). “Diffusion by continuous movements”. Proc. London Math. Soc. Ser. A. 20, 196-211.

Williamson, D.L. and Rasch, P.J. (1989) “Two-dimensional semi-Lagrangian transport with shape-preserving interpolation”, Monthly Weather Review, 117, 102-129. 


\section{APPENDIX II. NOTATION}

The following symbols were used in this paper:
$a$
Exponent of the Kostiakov infiltration equation;
C
Fertilizer concentration $\left(\mathrm{M} \mathrm{L}^{-3}\right)$;
$D_{i}$
Infiltration momentum transfer;
$D U L Q_{F} \quad$ Fertilizer uniformity distribution of the low quarter (\%);
Fert $\quad$ Mass of fertilizer infiltrated during a time step $\left(\mathrm{M} \mathrm{L}^{-2}\right)$
$f_{0} \quad$ Parameter of the Kostiakov infiltration equation $\left(\mathrm{LT}^{-1}\right)$;
h $\quad$ Water depth (L);
i Infiltration rate $\left(\mathrm{LT}^{-1}\right)$;
$K x \quad$ Longitudinal dispersion coefficient $\left(\mathrm{L}^{2} \mathrm{~T}^{-1}\right)$;
$k \quad$ Parameter of the Kostiakov infiltration equation $\left(\mathrm{T}^{-\mathrm{a}}\right)$;
n Manning roughness coefficient;
Q Unit irrigation discharge $\left(\mathrm{L}^{2} \mathrm{~T}^{-1}\right)$;
$S_{0} \quad$ Bed slope;
$S_{f} \quad$ Energy grade slope;
Ta Starting time of fertilizer application ( $\mathrm{T}$ );
$u \quad$ Depth averaged water velocity $\left(\mathrm{LT}^{-1}\right)$; and
$u_{i} \quad$ i-component of velocity vector $\left(\mathrm{LT}^{-1}\right)$.
$\varepsilon_{i} \quad$ Turbulent diffusion coefficient in i-direction $\left(\mathrm{L}^{2} \mathrm{~T}^{-1}\right)$; 


\section{APENDIX III. FIGURES}

Figure 1. Fertilizer concentration histories at 50, 100 and $150 \mathrm{~m}$ down the border for the two steady state experiments. Observed and simulated data are presented. Simulations include linear and cubic interpolations with different values of the longitudinal dispersion coefficient (expressed in $\mathrm{m}^{2} \mathrm{~s}^{-1}$ ).

Figure 2. Fertilizer concentration histories at 50, 100 and $150 \mathrm{~m}$ down the border for the two unsteady state experiments. Observed and simulated data are presented. Simulations include linear and cubic interpolations with different values of the longitudinal dispersion coefficient (expressed in $\mathrm{m}^{2} \mathrm{~s}^{-1}$ ).

Figure 3. Fertilizer concentration histories at several distances down the border for the bromide experiment reported by Playán and Faci (1997). Observed and simulated data are presented. Simulations include linear and cubic interpolations with different values of the longitudinal dispersion coefficient (expressed in $\mathrm{m}^{2} \mathrm{~s}^{-1}$ ).

Figure 4 .Sensitivity analysis of $D U L Q_{F}$ to the value of $K x$. Four cases are presented. In all of them fertilizer application starts at time $377 \mathrm{~s}$. The application ended at times 754, 1,131, 1,250 and 1,886 s for cases S1, S2, S3 and S4, respectively.

Figure 5. Contour line map of $D U L Q_{F}$ for different values of the fertilizer starting and ending time for the bromide experiment reported by Playán and Faci (1997). Results are presented for the advection model presented by Playán and Faci (1997) and the proposed model (using $K x=0.075 \mathrm{~m}^{2} \mathrm{~s}^{-1}$ ). 
Figure 6. Scatter plot of the $D U L Q_{F}$ obtained with an advection model and the proposed model. The data corresponds to the simulation of the Bromide experiment reported by Playán and Faci (1997) using a variety of starting and ending fertilizer application times. 


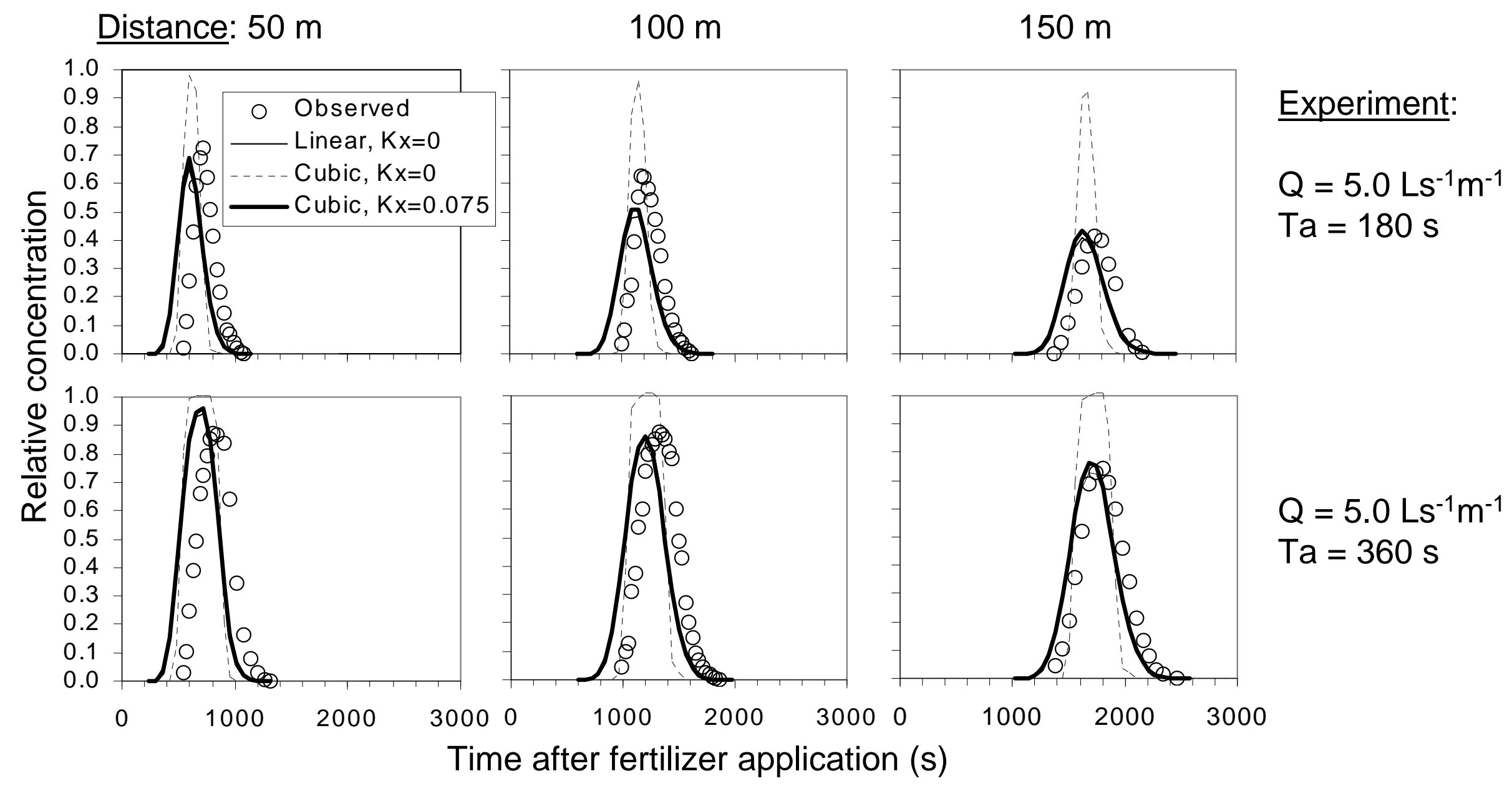




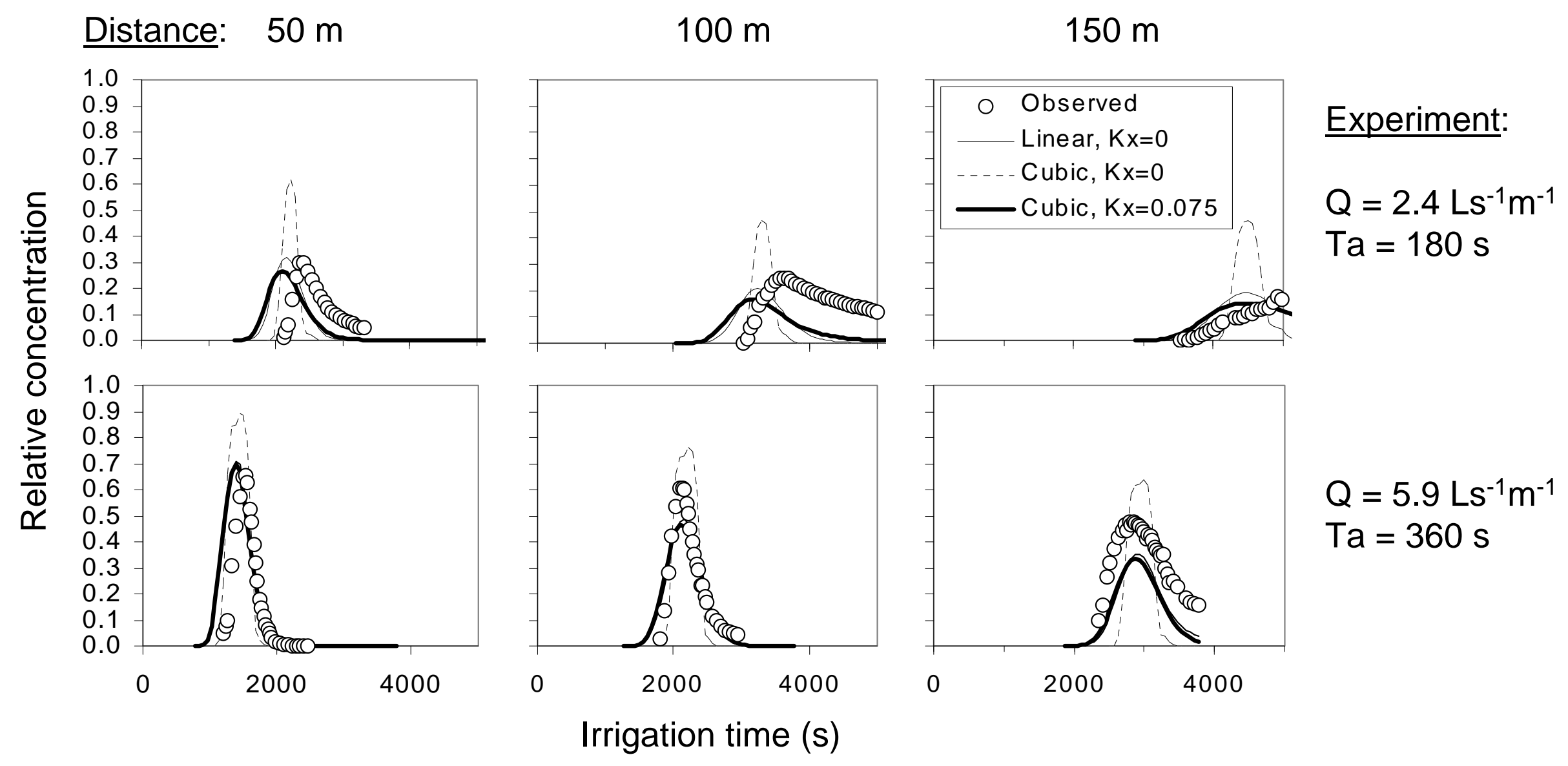



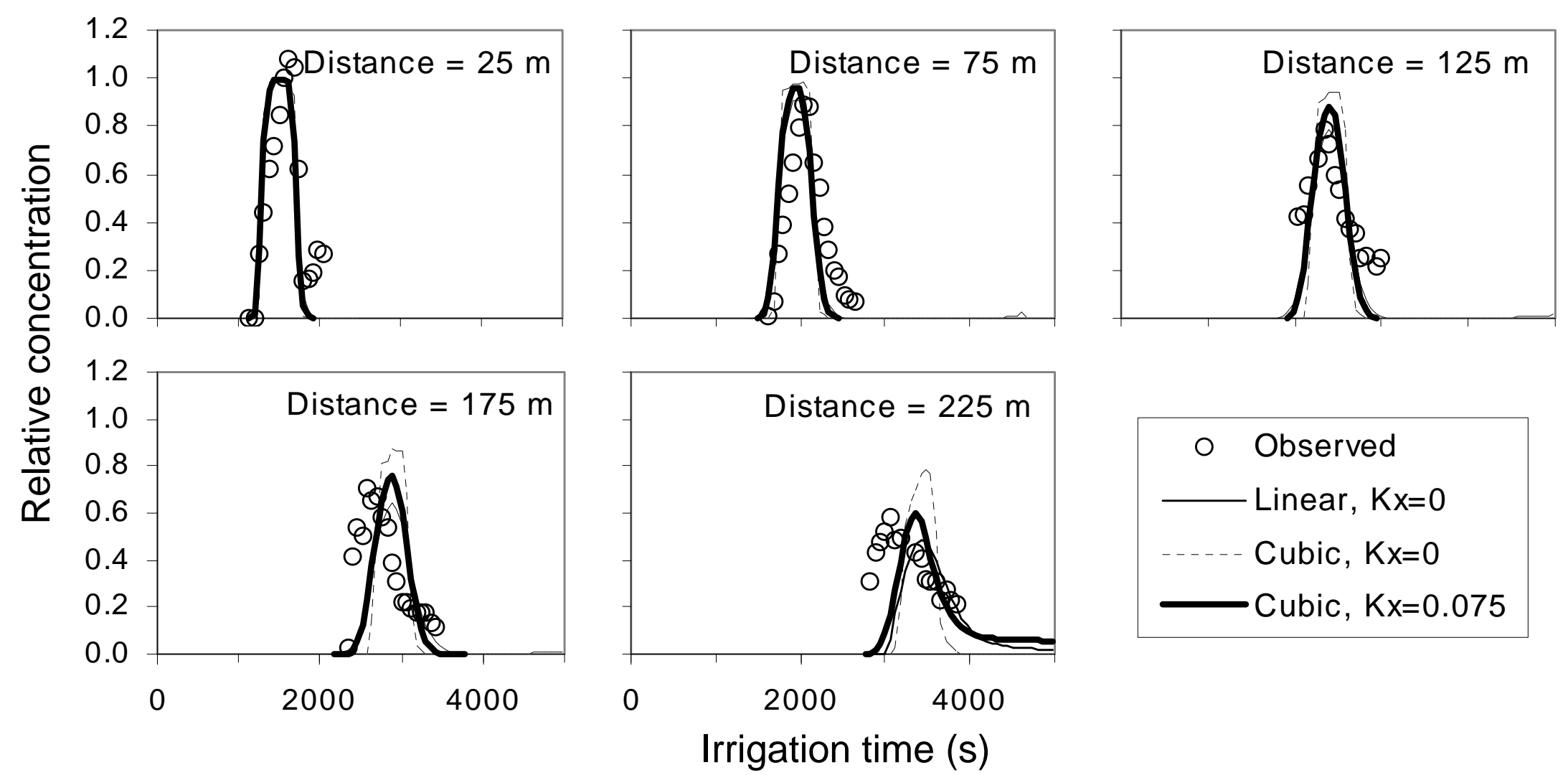


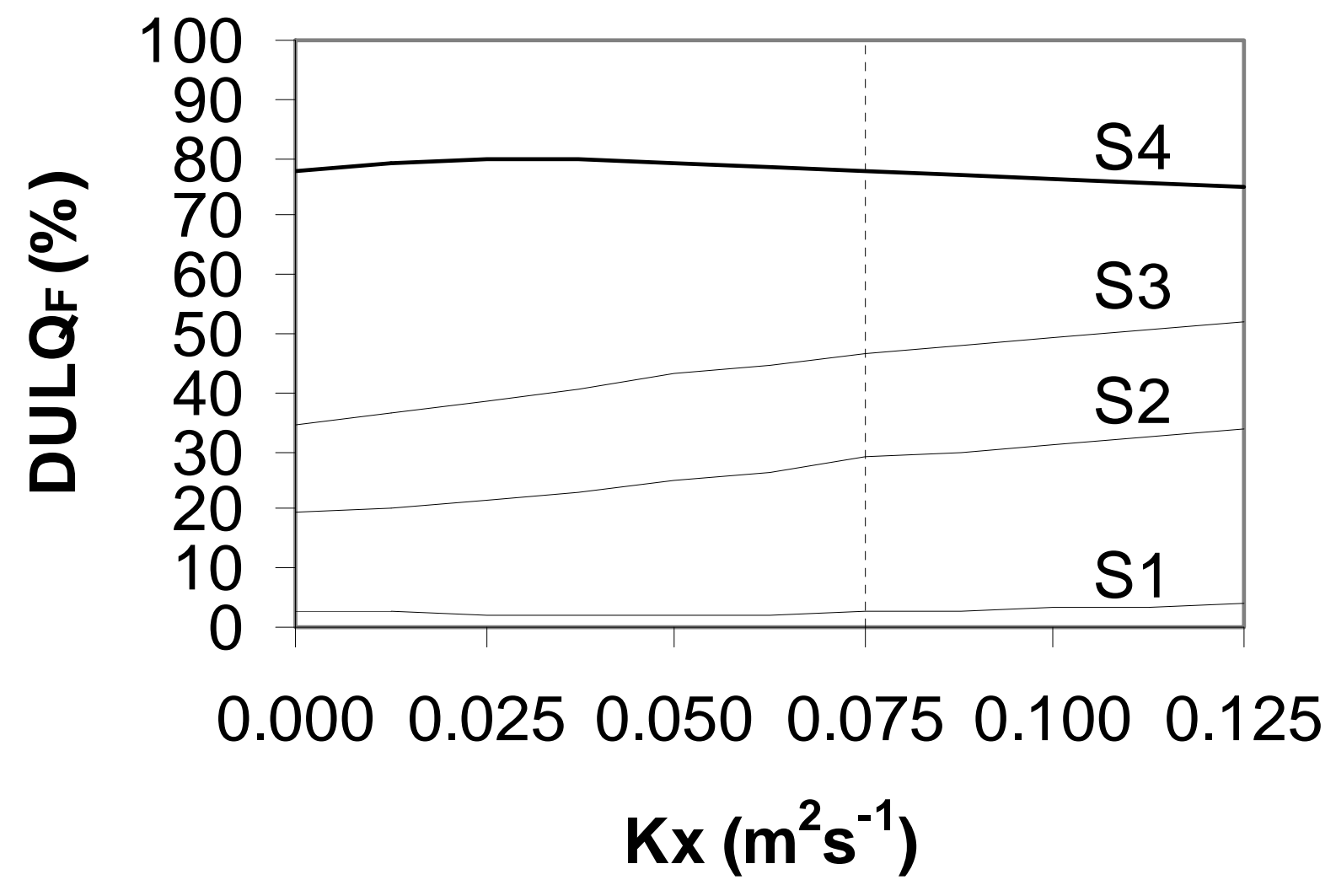




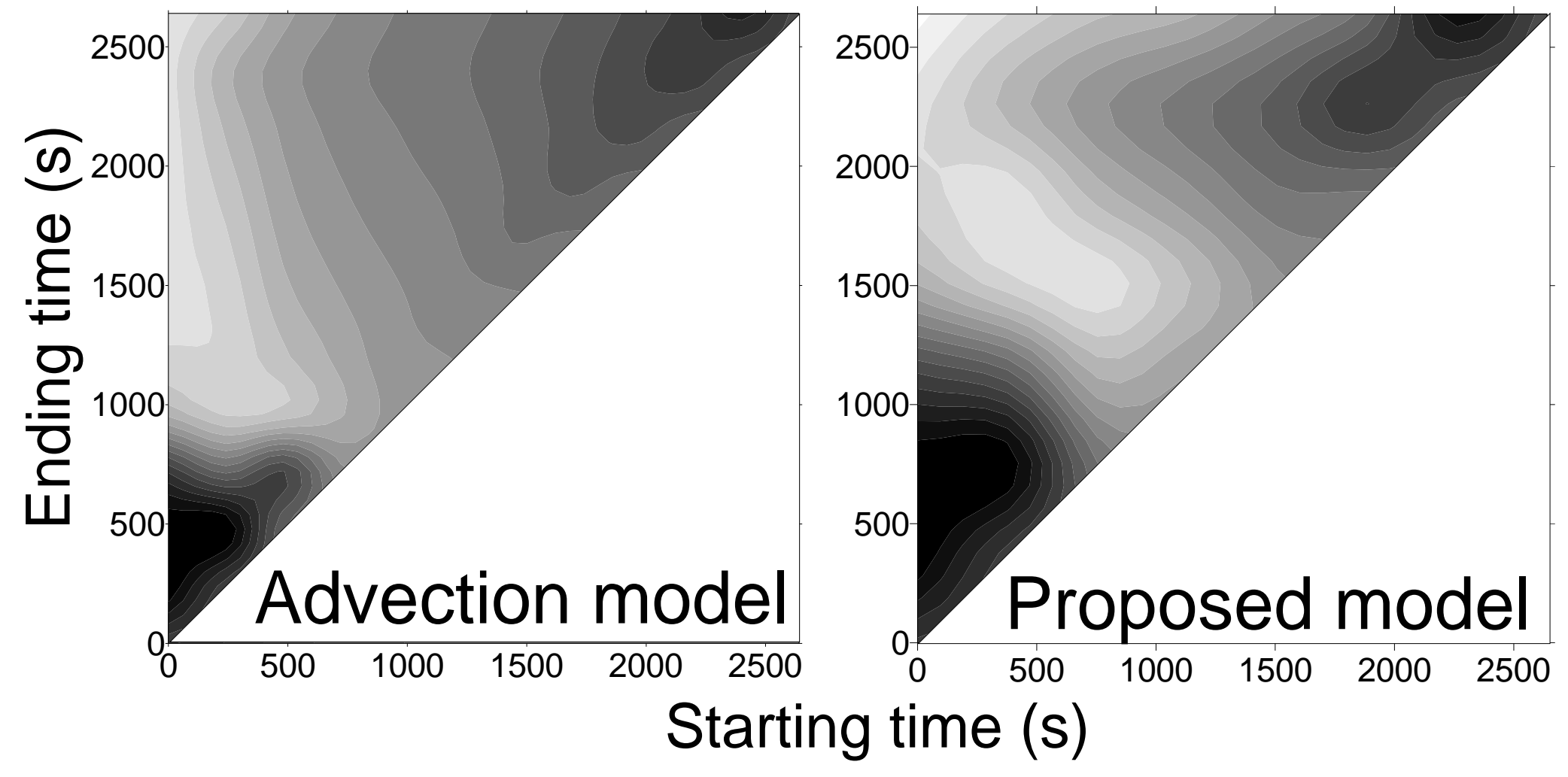

01020304050607080 


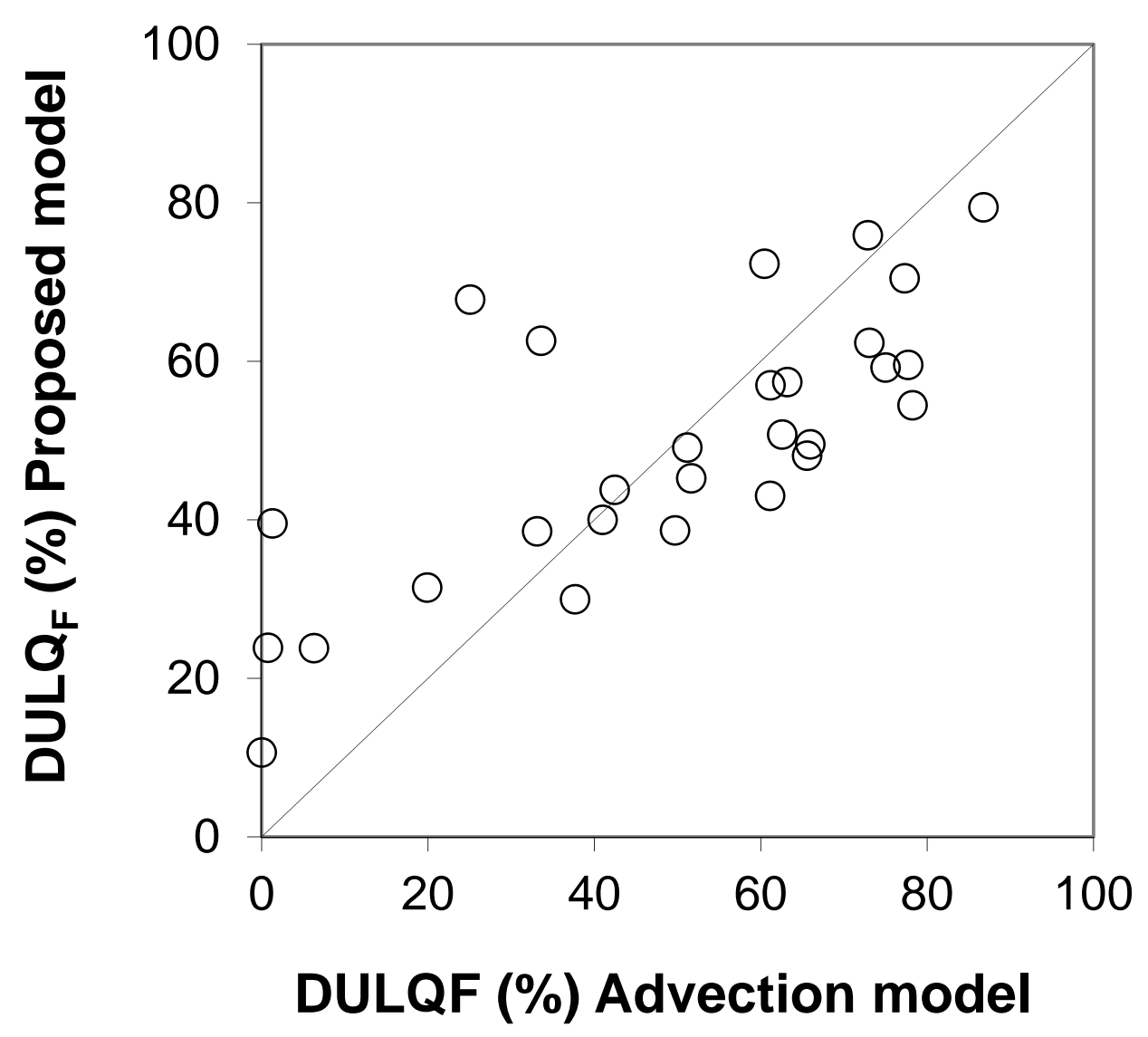

